\title{
Technical feasibility and intermediate outcomes of using a handcrafted, area-preserving, bifurcated Y-graft modification of the Fontan procedure
}

\author{
Mary Hunt Martin, MD, ${ }^{\mathrm{a}}$ Jeffrey A. Feinstein, MD, MPH, ${ }^{\mathrm{b}, \mathrm{c}}$ Frandics P. Chan, MD, ${ }^{\mathrm{d}}$ \\ Alison L. Marsden, $\mathrm{PhD},{ }^{\mathrm{e}}$ Weiguang Yang, $\mathrm{PhD},{ }^{\mathrm{b}}$ and $\mathrm{V}$. Mohan Reddy, $\mathrm{MD}^{\mathrm{f}}$
}

Objectives: To demonstrate the technical feasibility and describe intermediate outcomes for the initial patients undergoing handcrafted, area-preserving, Y-graft modification of the Fontan procedure.

Methods: A retrospective review of a pilot study was undertaken to describe preoperative, intraoperative, and postoperative results.

Results: Six patients underwent successful procedures and remain alive 3 to 4 years later. The median age at operation was 3.3 years, and median weight was $13.2 \mathrm{~kg}$. Five operations were done without cardiopulmonary bypass and no intraoperative pressure gradients were found. Five patients were extubated by postoperative day 1 , Fontan pressures were 12 to $14 \mathrm{~mm} \mathrm{Hg}$, transpulmonary gradients were 6 to $8 \mathrm{~mm} \mathrm{Hg}$, and no renal or hepatic function abnormalities were found. Length of stay was 10 to 64 days. One patient required venovenous extracorporeal membrane oxygenation for previously undiagnosed plastic bronchitis (64-day stay); another required reoperation for an incidentally diagnosed aortic thrombus (44-day stay). One patient had occlusion of a Y-graft limb noted on magnetic resonance imaging follow-up at 3 months. Catheterization showed excellent hemodynamic parameters and no Fontan obstruction. Occlusion was believed to be due to right-sided pulmonary arteriovenous malformations and widely discrepant flow $(80 \%)$ to the right lung leading to low flow in the left limb.

Conclusions: The area-preserving, bifurcated Y-graft Fontan modification is technically feasible and shows excellent intermediate outcomes. Additional study is required to determine whether the advantages seen in the computational models will be realized in patients over the long-term, and to optimize patient selection for each of the various Fontan options now available. (J Thorac Cardiovasc Surg 2015;149:239-45)

See related commentary on page 246.

Video clip is available online.

From the Department of Pediatrics (Cardiology), ${ }^{\mathrm{a}}$ University of Utah, Salt Lake City, Utah; Departments of Pediatrics (Cardiology), ${ }^{\mathrm{b}}$ Bioengineering, ${ }^{\mathrm{c}}$ Radiology, ${ }^{\mathrm{d}}$ and Cardiothoracic Surgery, ${ }^{\mathrm{f}}$ Stanford University, Palo Alto, Calif; and Department of Mechanical and Aerospace Engineering, ${ }^{\mathrm{e}}$ University of California San Diego, La Jolla, Calif.

Supported in part by the Leducq Foundation (A.L.M.), a Burroughs Wellcome Fund Career Award at the Scientific Interface (A.L.M.), and the American Heart Association Beginning Grant-in-Aid (A.L.M. and W.Y.). Nonfinancial support (ie, materials) were provided by W. L. Gore \& Associates, Inc, Flagstaff, Ariz.

Disclosures: Authors have nothing to disclose with regard to commercial support.

May Hunt Martin and Jeffrey A. Feinstein are co-first authors.

Received for publication March 26, 2014; revisions received Aug 16, 2014; accepted for publication Aug 23, 2014; available ahead of print Oct 16, 2014.

Address for reprints: Jeffrey A. Feinstein, MD, MPH, Division of Pediatric Cardiology, Stanford University School of Medicine, 750 Welch Rd, Suite 305, Palo Alto, CA 94304 (E-mail: Jeff.Feinstein@ stanford.edu).

$0022-5223 / \$ 36.00$

Copyright $(\odot) 2015$ by The American Association for Thoracic Surgery

http://dx.doi.org/10.1016/j.jtcvs.2014.08.058
Supplemental material is available online.

The numerous modifications to the surgical approach for patients with single ventricle anatomy have, over the past several decades, led to improved short- and long-term outcomes. ${ }^{1}$ Although results have improved overall, patients undergoing Fontan procedure still experience significant long-term morbidity, exercise intolerance, and reduced quality of life. In many cases, it is unclear why a Fontan fails; however, it is generally agreed upon that optimizing the factors known to be detrimental is key to clinical success and even small changes may yield large benefits. ${ }^{2,3}$ Other morbidities such as the formation of pulmonary arteriovenous malformations are related to the distribution of hepatic blood flow. ${ }^{4}$

Since the initial, atriopulmonary connection was described, significant modifications have been implemented, most notably the total cavopulmonary connection and its lateral tunnel and extracardiac forms. Computational simulation studies show that by offsetting the anastomotic site of the inferior vena cava (IVC) baffle/conduit into the pulmonary arteries, lower energy loss can be achieved in comparison to the 


\section{Abbreviations and Acronyms \\ IVC $=$ inferior vena cava \\ $\mathrm{MRI}=$ magnetic resonance imaging \\ $\mathrm{SCV}=$ superior vena cava}

traditional T-shaped junction. ${ }^{5-7}$ Although this modification is more energy-efficient, it often results in disproportionate distribution of the superior vena cava (SVC) and IVC flow with the majority of the SVC flow going the right pulmonary artery, and the majority of the IVC flow-and hepatic factor-going to the left pulmonary artery. ${ }^{8,9}$ This has led some to question the relative advantages of the offset model and return to the traditional T-shaped configuration. These factors led our group, and others, to investigate a more optimal Fontan geometry, one in which efficiency is preserved, Fontan pressures are minimized, and IVC blood flow is more equally distributed to the right and left lungs.

In one attempt, the OptiFlo Fontan configuration, idealized experimental and computational models were created, featuring bifurcated SVC and IVC anastomoses. ${ }^{10}$ Although computationally more energy efficient than the offset model, it was not adopted by clinicians. It was believed to be more technically complex than necessary, and the addition of the Dacron SVC baffle far less appealing than the traditional tissue-tissue anastomosis. ${ }^{11}$ Shortly thereafter, our group evaluated the effects of bifurcating the IVC baffle/conduit alone, in a patient-specific model. ${ }^{9}$ Two types of Y-shaped grafts were compared, one a commercially available, off-the-shelf variety, featuring an 18-mm trunk and two 9-mm legs, and the other a more physiologically inspired branched graft that would require handcrafting by the surgeon but preserves the cross-sectional area from the trunk into the 2 branches. The handcrafted graft was found to show superiority in energy efficiency, IVC and SVC pressure, and hepatic flow distribution. 9,12

Whereas both variations of the Y-graft were believed to be more technically feasible than the OptiFlo, initial clinical interest was tepid. It is technically more complex than the current, single- baffle method, and the need for handcrafting led to questions of technical feasibility and suture line complications. Other concerns included the risk of thrombosis in the graft legs, kinking, and impingement of the graft legs on surrounding structures.

Given the unequal IVC flow distribution resulting from the standard offset configuration, and the superiority demonstrated by computational modeling, 1 of our surgeons adopted the handcrafted, Y-graft modified Fontan procedure as his standard approach in 2010. We present the initial technical results, short and intermediate outcomes, and lessons learned from the first group of patients to undergo the handcrafted Y-graft Fontan procedure modification.

\section{METHODS}

Because the surgeon chose to perform the Y-graft as the standard approach, all patients referred to him for Fontan completion were potential candidates for inclusion in this observational study. Patients were excluded preoperatively if they had a history of clot formation or diagnosed hypercoaguable state. Families were informed the surgery to be performed was a variation on the current practice, the surgeon had adopted this new approach, and we would follow the patient during hospitalization and as an outpatient. They were also told the final decision regarding technical feasibility would be made by the surgeon in the operating room after inspecting the patient's anatomy and should the surgeon determine the Y-graft was not technically feasible, the patient would be excluded from the study. This study was approved by the institutional review board and informed consent was obtained from each participant's legal guardian(s).

Although each patient had individual anatomic variations, the noncardiopulmonary bypass procedure was accomplished as follows: the ascending aorta; main, right, and left pulmonary arteries; SVC; IVC; and right atrium were thoroughly and extensively dissected. Y-grafts were then constructed by hand using an 18-mm Gore-Tex (W. L. Gore \& Associates, Inc, Flagstaff, Ariz) trunk and two 12-mm Gore-Tex limbs (Figure 1). The angle between limbs was adjusted based on the intraoperative pulmonary artery anatomy. The right limb was angled at $30^{\circ}$ to $45^{\circ}$ and the left angled at $45^{\circ}$ to $60^{\circ}$, to prevent distortion of the left limb as it coursed over the top of the right atrium. The patient was fully heparinized and the left pulmonary artery was isolated with pursestring sutures. A pulmonary arteriotomy was made, and the left limb of the Y-graft was anastomosed to the left pulmonary artery in an end-to-side fashion using 6-0 Prolene (Ethicon Inc, Somerville, NJ) continuous suture. The graft was filled and clamped, and the pursestring sutures were released, reestablishing blood flow to the left pulmonary artery. The right pulmonary artery was then occluded with a side-biting clamp, an arteriotomy was made, and the right limb of the Y-graft was anastomosed in an end-to-side fashion. The entire tube graft was then flushed and filled with heparinized saline. The main trunk of the Y-graft was tailored to fit into the IVC, cut at the appropriate length, and anastomosed in the standard fashion. An example of the surgical procedure is provided in Video 1, and examples of 3-dimensional magnetic resonance imaging (MRI) reconstructions are shown in Figure E1.

Because fresh Gore-Tex grafts often cannot be imaged adequately by echocardiogram, the technical modification was new, and echocardiogram was believed to be insufficient to fully evaluate the Y-graft, MRI was performed in the immediate postoperative period. If the MRI would lead to a discharge delay, it was performed while the patient was an outpatient. Each family was given the option of having the child return for a follow-up, no-cost, MRI 6 months later for both ongoing clinical assessment of the Y-graft and research purposes.

Whereas the postoperative care providers knew the Y-graft had been performed (ie, they were not blinded to the procedure), no changes were made to the standard postoperative management of these patients with the exception of the MRI noted above. Specifically, diuretic management, anticoagulation practice (warfarin with a target international normalized ratio of 1.5-2.0), and indications for chest tube removal were per the standard protocols. Patients were discharged to follow-up with their primary cardiologists who provided the intermediate clinical data. No additional visits or testing on the part of the patient or family was required as part of this study.

Preoperative data collection included medical history, laboratory work, electrocardiogram, echocardiogram, and pre-Fontan cardiac catheterization details. Intraoperative data included the technical details of graft creation and operative procedure, duration of operation, Fontan circuit pressures, echocardiogram findings (both pre- and postoperative), and complications. Postoperative data included the transpulmonary gradient via Fontan and atrial lines (placed routinely in our practice), time to extubation, routine blood work (eg, kidney and liver function tests), chest tube drainage duration, length of stay, adverse events, and results of the discharge MRI. After discharge, intermediate follow-up data was 

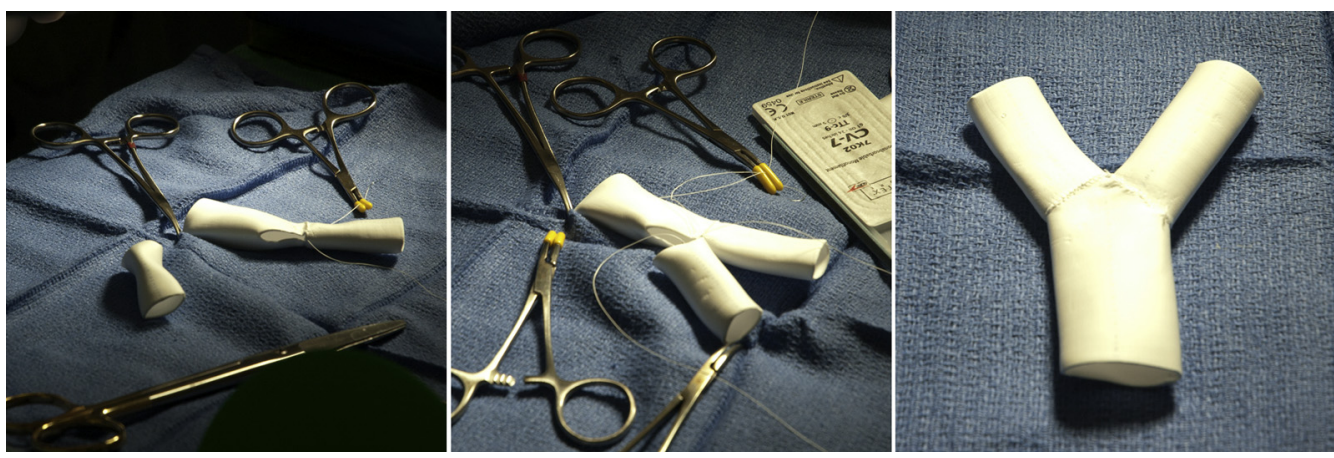

FIGURE 1. Construction of the Y-graft. Left, The trunk is cut to approximate a $90^{\circ}$ angle between limbs and the right limb is attached. Middle, The left limb is attached. Right, The final Y-graft to be implanted.

collected from primary cardiologist clinic letters; telephone calls; a review of the testing performed (eg, echocardiograms, Holters, and cardiac catheterizations); and the results of 6-month MRIs, if performed.

\section{RESULTS}

Between July 2010 and May 2011, 9 patients were candidates for Y-graft modified Fontan operation, and 6 underwent the procedure. Two were not candidates during this initial phase of implementation due to a history of hypercoagulability and 1 patient was not attempted due to unfavorable anatomy. Patient demographics, and summaries of their medical histories and preoperative testing are presented in Table 1. The median age at operation was 3.3 years (range, 2.8-4.2 years) and the median weight was $13.2 \mathrm{~kg}$ (range, $11.8-15.5 \mathrm{~kg}$ ).

\section{Immediate Postoperative Outcomes}

There were no deaths, no major intraoperative complications, and no hemodynamically significant arrhythmias.

TABLE 1. Patient demographics and preoperative testing results

\begin{tabular}{|c|c|c|c|c|c|c|c|c|c|}
\hline \multirow[b]{2}{*}{ Patient } & \multirow[b]{2}{*}{ Age, $y$} & \multirow[b]{2}{*}{ Weight, kg } & \multirow[b]{2}{*}{ Primary diagnosis } & \multirow{2}{*}{$\begin{array}{c}\text { Prior cardiac } \\
\text { operations }\end{array}$} & \multirow[b]{2}{*}{ Comorbidities } & \multirow{2}{*}{$\begin{array}{c}\text { Echocardiogram } \\
\text { findings } \\
\end{array}$} & \multicolumn{3}{|c|}{ Cardiac catheterization } \\
\hline & & & & & & & Ao sat, $\%$ & PVR (WU) & CI \\
\hline 1 & 3.3 & 14 & $\begin{array}{l}\text { DORV, mitral } \\
\text { stenosis, TAPVR }\end{array}$ & $\begin{array}{l}\text { 1. PA band } \\
\text { 2. Atrial septectomy } \\
\text { 3. BDG }\end{array}$ & $\begin{array}{l}\text { Reactive airway } \\
\text { disease }\end{array}$ & $\begin{array}{l}\text { Mild TR, normal } \\
\text { function }\end{array}$ & 83 & 1.8 & 3 \\
\hline 2 & 2.8 & 15.5 & HLHS (MS/AA) & $\begin{array}{l}\text { 1. Norwood/Sano, } \\
\text { atrial septectomy } \\
\text { 2. BDG, PA-plasty }\end{array}$ & $\begin{array}{l}\text { SVT; left vocal } \\
\text { cord paralysis }\end{array}$ & $\begin{array}{l}\text { Trace TR, neo-AI, } \\
\text { mildly depressed } \\
\text { RV function }\end{array}$ & 81 & 1.7 & 4.3 \\
\hline 3 & 3.3 & 14 & $\begin{array}{l}\text { DORV, D-TGA, } \\
\text { pulmonary } \\
\text { stenosis }\end{array}$ & $\begin{array}{l}\text { 1. PA band } \\
\text { 2. PA band loosening } \\
\text { 3. Atrial septectomy } \\
\text { 4. BDG }\end{array}$ & $\begin{array}{l}\text { Reactive airways } \\
\text { disease; } \\
\text { polydactyly }\end{array}$ & $\begin{array}{l}\text { Mild TR, } \\
\text { normal function }\end{array}$ & 84 & 0.9 & 5.3 \\
\hline 4 & 4.2 & 11.9 & HLHS & $\begin{array}{l}\text { 1. Norwood/Sano, } \\
\text { atrial septectomy } \\
\text { 2. BDG }\end{array}$ & Failure to thrive & $\begin{array}{l}\text { No TR, } \\
\text { normal function }\end{array}$ & 85 & 1.3 & 6 \\
\hline 5 & 3.4 & 11.8 & $\begin{array}{l}\text { DORV, mitral } \\
\text { atresia, hypoplastic } \\
\text { aortic arch }\end{array}$ & $\begin{array}{l}\text { 1. Coarctation repair, } \\
\text { PA band } \\
\text { 2. PA band loosening } \\
\text { 3. Atrial septectomy, } \\
\text { mBTS } \\
\text { 4. DKS, BDG, RPA, } \\
\text { and LPA plication }\end{array}$ & $\begin{array}{l}\text { Prematurity } \\
\text { (34 wk); } \\
\text { GE reflux }\end{array}$ & $\begin{array}{l}\text { No TR, trace neo-AI, } \\
\text { low-normal function }\end{array}$ & 78 & 0.7 & 6.2 \\
\hline 6 & 3.2 & 12.3 & $\begin{array}{l}\text { HLHS, restrictive } \\
\text { atrial septum }\end{array}$ & $\begin{array}{l}\text { 1. Atrial septal stent } \\
\text { 2. Norwood/Sano, } \\
\text { atrial septectomy } \\
\text { 3. Emergent mBTS } \\
\text { 4. BDG }\end{array}$ & $\begin{array}{l}\text { SVT; Plastic } \\
\text { bronchitis* }\end{array}$ & $\begin{array}{l}\text { Mild TR, } \\
\text { normal function }\end{array}$ & 86 & 1.2 & 4.7 \\
\hline
\end{tabular}

Ao Sat, Aortic saturation; $P V R$, pulmonary vascular resistance; $W U$, Woods units; $C I$, cardiac index; DORV, double outlet right ventricle; TAPVR, total anomalous pulmonary venous return; $B D G$, bidirectional Glenn shunt; $T R$, tricuspid regurgitation; $H L H S$, hypoplastic left heart syndrome; $M S$ - $A A$, mitral stenosis with aortic atresia; Sano, Sano shunt; $P A$, pulmonary artery; $S V T$, supraventricular tachycardia; $A I$, aortic insufficiency; $R V$, right ventricle; $D$ - $T G A$, D-transposition of the great arteries; $m B T S$, modified BlalockTaussig shunt; $D K S$, Damus-Kaye-Stansel; $R P A$, right pulmonary artery; $L P A$, left pulmonary artery; $G E$, gastroesophageal. *Noted after the Fontan but subsequently found to have been present before the Fontan. 
Five of 6 operations were done without cardiopulmonary bypass. Patient 5 was placed on bypass due to intermittent unstable junctional rhythm while the chest was being opened. Intraoperative pressure measurements were obtained from the SVC, IVC, and both pulmonary arteries, and no pressure gradients were found in any patient. With the exception of patient 6 (see below), all patients were extubated within the first 24 hours postoperatively. On the day of extubation, the pressures in the Fontan circulation ranged from 12 to $14 \mathrm{~mm} \mathrm{Hg}$, atrial pressures ranged from 4 to 6 $\mathrm{mm} \mathrm{Hg}$, and transpulmonary gradients ranged from 6 to 8 $\mathrm{mm} \mathrm{Hg}$. The length of stay ranged from 10 to 64 days $(22,32,10,44,38$, and 64 days in patients 1-6, respectively). No laboratory evidence of renal or hepatic function abnormalities were found in any patient.

Patients 1,2, 3, and 5 had uneventful postoperative courses, with the exception of prolonged chest tube drainage in patients 2 and 5 requiring a longer than usual hospital stay when compared with our institutional historical controls. Patient 4 required reoperation on postoperative day 12 for a native aortic root thrombectomy after a thrombus was discovered on a routine echocardiogram. This patient also required pericardiocentesis on postoperative day 39 for a stable, large, pericardial effusion. Patient 6 required venovenous extracorporeal membrane oxygenation in the immediate postoperative period due to what was initially thought to be lung injury, later found to be plastic bronchitis. Further history revealed that the patient had actually produced casts in the past, before his Fontan operation; however, this was not known to his care providers.

Imaging in the immediate postoperative period $(\mathrm{MRI} \times 3$, computed tomography $\times 2$ ) showed no obstructive thrombus or occlusion within the Fontan circuit in patients 1 through 4 , and 6 . Patients 4 and 6 did have a small, nonobstructing layer of adherent clot versus endothelialization in the common trunk and the left limb of the Y-graft. Patient 5 was discharged without undergoing MRI and was lost to follow-up until 3 months postoperatively. MRI at that time showed complete occlusion of the left limb of the Y-graft (Figure 2). Cardiac catheterization was performed and demonstrated excellent hemodynamic parameters with a cardiac index of $3.7 \mathrm{~L} / \mathrm{m} / \mathrm{m}^{2}$, Fontan pressures of 11 to 12 $\mathrm{mm} \mathrm{Hg}$, no gradient to the right pulmonary artery, a 2-mm $\mathrm{Hg}$ gradient to the left pulmonary artery, normal pulmonary vascular resistance index, and confirmed the occlusion of the left limb (Figure E2). Given the excellent hemodynamic parameters and potential risks (eg, limb perforation and clot dislodgement), no attempts were made to recannulate the limb.

\section{Short-Term Outcomes}

No adverse events occurred between the time of discharge and 6-month follow-up. All 6 patients consented to the 6-month, voluntary MRI; however, only 4 underwent the test. Given the history of plastic bronchitis and need for intubation, it was decided patient 6 should not be rescanned. Additionally, because the previous scan for patient 5 was only 3 months earlier, the left limb was already known to be occluded, and no clinically important or research data were likely to be found, the patient was not rescanned. MRI was performed uneventfully in the other 4 patients; right and left lung blood flow distribution were, in general, equally matched. These results are summarized in Table 2. Aside from the occlusion of the left limb in patient 5, no evidence of clot or limb occlusion was noted, and there was no evidence of distortion of the Fontan circuit, pulmonary arteries, or adjacent structures, and the Y-graft geometry was maintained. The cross-sectional area of the trunk and limbs are mildly reduced. Specifically, the average reduction in cross-sectional area of the 6-month model compared with the immediate postoperative model was $\sim 6 \%, 13 \%$, and $7 \%$ for the trunk, right limb, and left limb, respectively.

\section{Intermediate-Term Outcomes}

Patients have now been followed for an average of 3.2 years after their Y-graft procedure (range, 2.8-3.7 years). All 6 are alive and clinically well. All are asymptomatic with the exception of patient 6 who continues to have intermittent episodes of plastic bronchitis, although is otherwise asymptomatic. Because they have not been followed as part of a formal protocol, follow-up testing has been at the primary cardiologist's discretion. Patient 3 underwent cardiac catheterization for concerns of left pulmonary artery stenosis 2 years postoperatively. The Fontan circuit (including the left pulmonary artery) was widely patent, and hemodynamic parameters were excellent with a cardiac index of $3.8 \mathrm{~L} / \mathrm{m} /$ $\mathrm{m}^{2}$, transpulmonary gradient of $6 \mathrm{~mm} \mathrm{Hg}$, and a pulmonary vascular resistance index of 1.8 Woods units. The current status of the 6 patients is summarized in Table 3.

\section{DISCUSSION}

The Fontan remains a suboptimal form of definitive palliation for many patients with only a single functional ventricle. In an effort to improve upon the existing forms of total cavopulmonary anastomosis, using computational simulation methods, we and others have investigated a modification to current extracardiac grafts that require bifurcating the IVC to a pulmonary artery baffle. In our simulation studies, preservation of cross-sectional area (and by association, physiology, and energy efficiency) and optimal hemodynamic parameters and biomechanical properties required $18-\mathrm{mm}$ trunks and $12-\mathrm{mm}$ limbs. ${ }^{9}$ This combination is not available commercially (ie, off the shelf) and others have chosen to use off-the-shelf grafts with 18-mm trunks and 9-mm limbs. Although technically more complicated and time-consuming, we believed the potential benefits of handcrafting the Y-graft outweighed the additional surgeon effort and time required. 

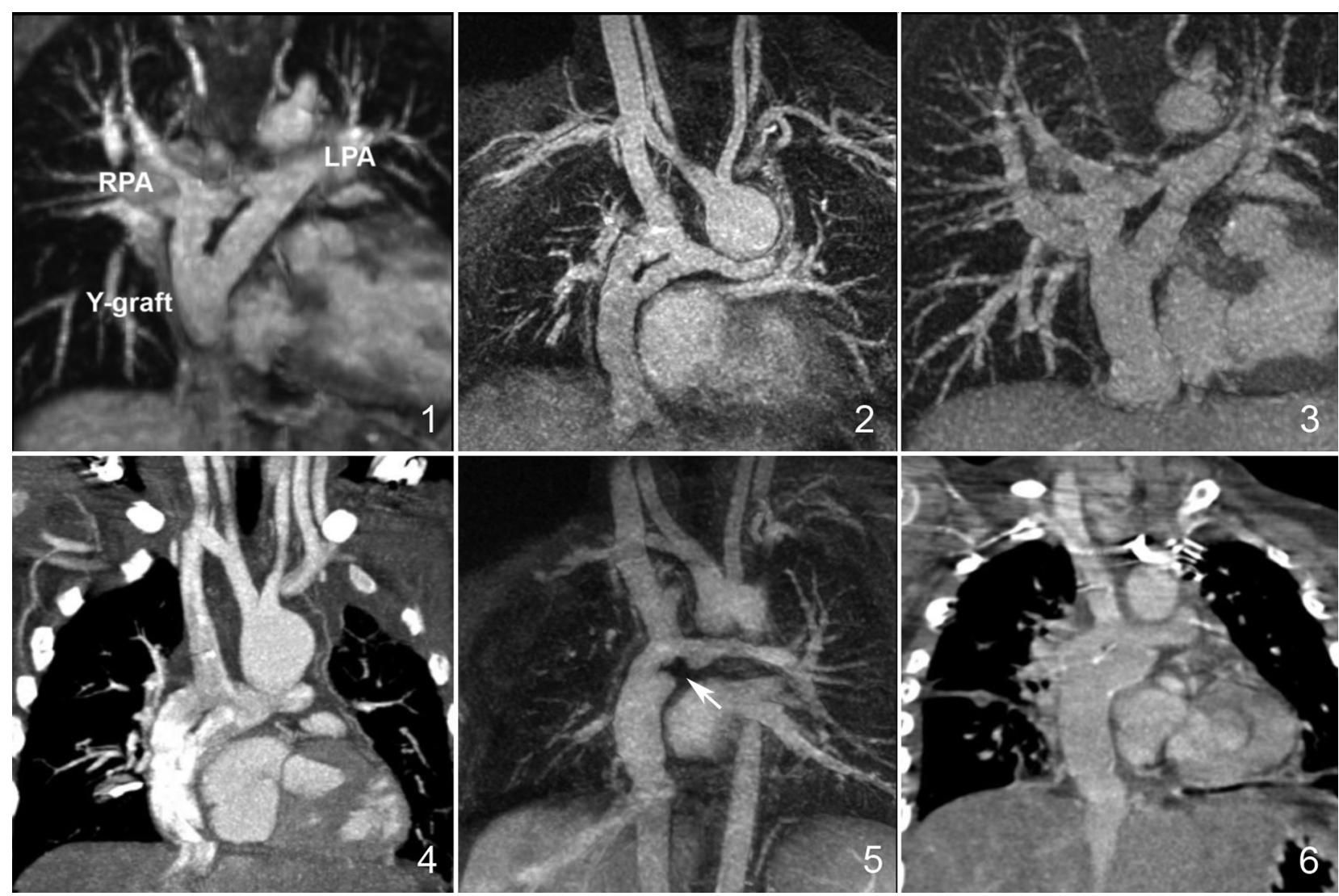

FIGURE 2. Reconstructed, orthogonal images of the Y-graft in the 6 pilot patients. A filling defect between stumps of the left limb of patient 5 represents an organized thrombus and limb occlusion (arrow). Images were reconstructed to optimize visualization of Y-graft and may misrepresent pulmonary artery distortion and stenosis. Images 1, 2, 3, and 5 are magnetic resonance imaging, whereas images 4 and 6 are computed tomography. RPA, Right pulmonary artery; $L P A$, left pulmonary artery.

In this unblinded pilot study, we demonstrated technical feasibility, safety, and comparable short and intermediate outcomes of a bifurcated, handcrafted, area-preserving, extracardiac Fontan graft. Each of the 6 patients successfully underwent placement of the $1812 \times 2$ grafts without distortion of nearby structures, and remain alive and clinically asymptomatic 3 to 4 years after their operation. No patient required cardiopulmonary bypass strictly for technical reasons related to the Y-graft. Our small study was not designed or powered to look at short-term outcome parameters. As is often the case with a small, nonmatched, pilot study, the patients included in our study were not, in some respects, representative of our historical population. Specifically, the median age of the 6 patients in this study was 3.3 years, and their median weight was $13.2 \mathrm{~kg}$, compared with our 5-year historical population who underwent their Fontan at a median age of 4.0 years (mean, 4.2 years) and a weight of $15 \mathrm{~kg}$.

TABLE 2. Anatomic and magnetic resonance imaging (MRI)-determined blood flow distribution results from the 4 MRI and 2 computed tomography (CT) scans performed before discharge

\begin{tabular}{|c|c|c|c|c|}
\hline \multirow[b]{2}{*}{ Patient } & \multicolumn{2}{|r|}{ Imaging } & \multicolumn{2}{|c|}{ Pulmonary vein flow split } \\
\hline & Modality & Results & Right & Left \\
\hline 1 & MRI & Patent Fontan & $70^{*}$ & 30 \\
\hline 2 & MRI & Patent Fontan & 50 & 50 \\
\hline 3 & MRI & Patent Fontan; compression of left pulmonary vein & 56 & 44 \\
\hline 4 & $\mathrm{CT}$ & $\begin{array}{l}\text { Small layer of adherent clot vs endothelialization in Y-graft trunk and left limb, } \\
\text { no obstruction }\end{array}$ & & \\
\hline 5 & MRI & Y-graft left limb occluded $\dagger$ & 58 & 42 \\
\hline 6 & $\mathrm{CT}$ & $\begin{array}{l}\text { Small layer of adherent clot vs endothelialization in Y-graft trunk and left limb, } \\
\text { no obstruction }\end{array}$ & & \\
\hline
\end{tabular}

$N / A$, Not applicable; $M R I$, magnetic resonance imaging; $C T$, computed tomography. *Superior vena cava flow in patient 1 skewed to right lung because Y-graft distribution was $45 \%$ right limb, $55 \%$ left limb. †Initial MRI was performed 3 months postoperatively on patient 5 . 
TABLE 3. Current clinical status for the 6 pilot patients, on average, 3.2 y (range, 2.8-3.7 y) postoperatively

\begin{tabular}{|c|c|c|c|c|}
\hline Patient & Clinical status & Medications & Rhythm & Echocardiogram findings \\
\hline 1 & $\begin{array}{l}\text { "Clinically well and active," } \\
\text { Pulse oximeter, } 96 \%\end{array}$ & $\begin{array}{l}\text { Aspirin, furosemide } \\
\text { enalapril }\end{array}$ & $\begin{array}{l}\text { Sinus bradycardia; } \\
\text { Holter (-) }\end{array}$ & $\begin{array}{l}\text { Glenn and Fontan trunk unobstructed, } \\
\text { Y-graft not well seen, normal function, } \\
\text { mild tricuspid regurgitation }\end{array}$ \\
\hline 2 & $\begin{array}{l}\text { "Asymptomatic, lots of energy" } \\
\text { Pulse oximeter, } 95 \%\end{array}$ & $\begin{array}{l}\text { Aspirin, warfarin, furosemide, } \\
\text { spironolactone, enalapril, } \\
\text { digoxin }\end{array}$ & NSR; Holter (-) & $\begin{array}{l}\text { Visualized portions of Fontan circuit } \\
\text { patent, normal function; mild tricuspid } \\
\text { regurgitation }\end{array}$ \\
\hline 3 & "Stable," Pulse oximeter, 98\% & $\begin{array}{l}\text { Aspirin, spironolactone, } \\
\text { enalapril }\end{array}$ & NSR; Holter (-) & $\begin{array}{l}\text { Visualized portions of Fontan circuit } \\
\text { patent, normal function mild tricuspid } \\
\text { regurgitation }\end{array}$ \\
\hline 4 & $\begin{array}{l}\text { "Clinically well with good } \\
\text { energy," Pulse oximeter, } 94 \%\end{array}$ & $\begin{array}{l}\text { Aspirin, furosemide, } \\
\text { spironolactone, enalapril }\end{array}$ & Paced DDDR (sick sinus) & $\begin{array}{l}\text { Fontan circuit not well seen, normal } \\
\text { function }\end{array}$ \\
\hline 5 & $\begin{array}{l}\text { “Asymptomatic," Pulse } \\
\text { oximeter, } 95 \%\end{array}$ & $\begin{array}{l}\text { Aspirin, warfarin, } \\
\text { furosemide, spironolactone }\end{array}$ & $\begin{array}{l}\text { NSR; Holter - rare } \\
\text { PACs }\end{array}$ & $\begin{array}{l}\text { Visualized portions of Fontan circuit } \\
\text { patent, normal function, mild } \\
\text { ventricular dilation }\end{array}$ \\
\hline 6 & $\begin{array}{l}\text { “Asymptomatic," Pulse } \\
\text { oximeter, } 94 \%\end{array}$ & Aspirin, fluticasone & NSR; Holter (-) & $\begin{array}{l}\text { Visualized portions of Fontan circuit } \\
\text { patent, normal function }\end{array}$ \\
\hline
\end{tabular}

(-), Negative for arrhythmias; $N S R$, normal sinus rhythm; $D D D R$, dual pacing, dual sensing, dual response, rate adaptive; $P A C$, premature atrial contractions.

It has been established that, in general, the cross-sectional area-preserving Y-graft modification of the Fontan procedure is superior to previous offset designs in both energy efficiency and distribution of hepatic blood flow in computational models. ${ }^{9,12}$ This may not be the case for every patient. In addition, although Y-grafts (areapreserving and off the shelf) may result in superior energy efficiency, recent multiscale modeling suggests differences in energy efficiency may not result in significant changes in cardiac workload or other functional parameters as previously hypothesized. ${ }^{13}$

With regard to hepatic blood flow distribution, differences between the area-preserving graft and off-the-shelf products are less clear. Hepatic flow distribution largely depends on the anastomosis location and pulmonary flow split. ${ }^{12}$ Specifically, simulation work demonstrated the area-preserving graft would result in a slightly better IVC flow split, ${ }^{9}$ but is not a guarantee of even hepatic flow distribution. ${ }^{12}$

On a global scale, using the most advanced techniques currently employed, multiscale modeling of the Y-graft demonstrated no changes in pressure-volume loops or other parameters of clinical relevance in Y-graft when compared with traditional offset designs. ${ }^{13}$ It is worth noting that this was a study of only a single patient under resting conditions and conclusions should be drawn carefully.

The recent clinical experience of Kanter and colleagues ${ }^{11}$ details the first published cases of Y-graft implantation. They report on the use of the preassembled bifurcated Gore-Tex vascular graft composed of an 18-mm trunk and $29-\mathrm{mm}$ limbs in 6 patients. Cross-sectional vessel area is not preserved in these grafts because the total crosssectional area decreases from the trunk $\left(254 \mathrm{~mm}^{2}\right)$ to the branches $\left(127 \mathrm{~mm}^{2}\right)$. Loss of cross-sectional area potentially creates an effective stenosis, which could become more significant with growth or exercise.
This issue aside, their results were encouraging, but notable differences in patient characteristics and surgical technique were present. Patients were older, aged 2.1 to 18.9 years (mean, 7.2 years; median, 4.6 years); larger, weighing 10.3 to $50.1 \mathrm{~kg}$ (mean, $23.6 \mathrm{~kg}$; median, 18.1 $\mathrm{kg}$ ); all done using cardiopulmonary bypass; and fenestrated. Only 1 patient in our study underwent cardiopulmonary bypass and none were fenestrated per institution preference. Length of stay in their cohort was generally shorter, ranging from 6 to14 days. Two patients required early readmission for pleural effusions.

Although the use of cardiopulmonary bypass and fenestrations are associated with shorter lengths of stay, these do not likely represent the entire reason for the longer lengths of stay in our population. Of the 4 with longest stays, 1 experienced plastic bronchitis and 1 required reoperation for an aortic clot. The other 2 patients were otherwise without complication and deserve additional consideration. One possibility for the longer length of stay is the additional dissection required, especially in the absence of cardiopulmonary bypass, to place the bifurcated graft leading to increased pleural effusions. Additionally, patient weight in our cohort $(13.2 \mathrm{~kg})$ was far lower than the average of our historical Fontan patients $(15 \mathrm{~kg})$, and recent data has correlated low weight-for-age with increased morbidity and longer hospital stays..$^{14,15}$

Perhaps most concerning is the occlusion of the left limb in patient 5. By dividing the IVC flow between 2 limbs, reduced flow occurs in both. In addition, the suture lines resulting from handcrafting may contribute to the thrombotic risk, although in our limited study they did not appear to serve as the nidus for thrombus. Whereas the critical amount of flow leading to clinically important stasis and thrombosis formation in these new grafts is unknown, optimizing relative distribution would minimize these risks. In this 
particular patient, pulmonary arterial venous malformations in the right lung led to a large discrepancy in flow split $(80 \%$ through the right limb, $20 \%$ through the left limb), significant stasis in the left limb, and thrombus formation. Looking back, and knowing that, in general, arterial venous malformations resolve within 6 months of Fontan completion, multiple possibilities existed. Specifically, a Y-graft with smaller or unequal branches could have been constructed, the left limb of the Y-graft could have been anastomosed differently (to take advantage of SVC flow into the limb), or the traditional nonbifurcated offset graft could have been used. It is unlikely that a critical reduction in cross-sectional area was responsible for this event because those measured in this small group are less than that previously reported in the literature. ${ }^{16}$ This patient's experience underscores the need for patient-specific planning to select the optimal Fontan procedure, and in the case of the Y-graft, flow optimization for each graft limb. ${ }^{17}$

\section{Limitations}

The small number of patients included in our study, and lack of similarity with our larger historical controls, makes widespread application of the findings difficult, and, as such, one should proceed with caution before praising or condemning this new surgical approach. There is, in addition, some selection bias due to having excluded patients with a theorized risk of higher clotting potential. Finally, although no specific alterations in care were planned, treatment bias may exist.

\section{CONCLUSIONS}

We have demonstrated the technical feasibility of the handcrafted, area-preserving Y-graft modification of the total cavopulmonary anastomosis. Certainly questions remain as to whether this is a reasonable surgical option and additional study is required. It must be determined whether the advantages seen in the computational models will indeed be realized in patients over the long-term. Specifically, it is clear that one can achieve better hepatic blood flow distribution using the bifurcated technique (whether handcrafted or off the shelf) but the potential for thrombosis (both theoretical and real) may outweigh this advantage. Additional computational work has demonstrated that this risk can be better understood (and likely minimized) using patient-specific Y-graft design. ${ }^{18}$ One could easily foresee a paradigm incorporating preoperative imaging and multiscale modeling to predict postoperative outcomes leading to graft optimization or surgery customization in individual patients. Further study is also required to determine the importance of Fontan pathway energy loss (as a reason for the proposed modification) in this population and in the off-the-shelf Y-grafts, with considerations of both exercise and growth. As we continue this work, longer-term studies are needed to evaluate the differences in hepatic blood flow distribution, thrombosis, efficiency, and clinical outcomes among the 4 currently employed versions of the Fontan operation.

The authors thank Elisa McCarthy for her assistance in obtaining the clinical follow-up data from the 6 patients' primary cardiologists.

\section{References}

1. Bridges ND, Mayer JE Jr, Lock JE, Jonas RA, Hanley FL, Keane JF, et al. Effect of baffle fenestration on outcome of the modified Fontan operation. Circulation. 1992;86:1762-9.

2. Jaquiss R, Imamura M. Single ventricle physiology: surgical options, indications and outcomes. Curr Opin Cardiol. 2009;24:113-8.

3. Blaufox AD, Sleeper LA, Bradley DJ, Breitbart RE, Hordof A, Kanter RJ, et al Functional status, heart rate, and rhythm abnormalities in 521 Fontan patients 6 to 18 years of age. J Thorac Cardiovasc Surg. 2008;136:100-7. 107.e1.

4. Pike NA, Vricella LA, Feinstein JA, Black MD, Reitz BA. Regression of severe pulmonary arteriovenous malformations after Fontan revision and "hepatic factor" rerouting. Ann Thorac Surg. 2004;78:697-9.

5. De Leval MR, Kilner P, Gewillig M, Bull C. Total cavopulmonary connection: a logical alternative to atriopulmonary connection for complex Fontan operations. Experimental studies and early clinical experience. J Thorac Cardiovasc Surg. 1988;96:682-95

6. Dubini G, de Leval MR, Pietrabissa R, Montevecchi FM, Fumero R. A numerical fluid mechanical study of repaired congenital heart defects. Application to the total cavopulmonary connection. J Biomech. 1996;29:111-21.

7. Ensley AE, Lynch P, Chatzimavroudis GP, Lucas C, Sharma S, Yoganathan AP. Toward designing the optimal total cavopulmonary connection: an in vitro study. Ann Thorac Surg. 1999;68:1384-90.

8. Bove EL, de Leval MR, Migliavacca F, Guadagni G, Dubini G. Computational fluid dynamics in the evaluation of hemodynamic performance of cavopulmonary connections after the Norwood procedure for hypoplastic left heart syndrome. J Thorac Cardiovasc Surg. 2003;126:1040-7.

9. Marsden AL, Bernstein AJ, Reddy VM, Shadden SC, Spilker RL, Chan FP, et al. Evaluation of a novel Y-shaped extracardiac Fontan baffle using computational fluid dynamics. J Thorac Cardiovasc Surg. 2009;137:394-403.e2.

10. Soerensen DD, Pekkan K, de Zélicourt D, Sharma S, Kanter K, Fogel M, et al Introduction of a new optimized total cavopulmonary connection. Ann Thorac Surg. 2007;83:2182-90.

11. Kanter KR, Haggerty CM, Restrepo M, de Zelicourt DA, Rossignac J, Parks WJ, et al. Preliminary clinical experience with a bifurcated Y-graft Fontan procedurea feasibility study. J Thorac Cardiovasc Surg. 2012;144:383-9.

12. Yang W, Vignon-Clementel IE, Troianowski G, Reddy VM, Feinstein JA, Marsden AL. Hepatic blood flow distribution and performance in conventional and novel Y-graft Fontan geometries: a case series computational fluid dynamics study. J Thorac Cardiovasc Surg. 2012;143:1086-97.

13. Baretta A, Corsini C, Yang W, Vignon-Clementel IE, Marsden AL, Feinstein JA, et al. Virtual surgeries in patients with congenital heart disease: a multi-scale modeling test case. Philos Trans A Math Phys Eng Sci. 2011;369:4316-30.

14. Wallace MC, Jaggers J, Li JS, Jacobs ML, Jacobs JP, Benjamin DK, et al. Center variation in patient age and weight at Fontan operation and impact on postoperative outcomes. Ann Thorac Surg. 2011;91:1445-52.

15. Anderson JB, Kalkwarf HJ, Kehl JE, Eghtesady P, Marino BS. Low weight-forage $z$-score and infection risk after the Fontan procedure. Ann Thorac Surg. 2011; 91:1460-6.

16. Amodeo A, Galletti L, Marianeschi S, Picardo S, Giannico S, Di Renzi P, et al Extracardiac Fontan operation for complex cardiac anomalies: seven years' experience. J Thorac Cardiovasc Surg. 1997;114:1020-30.

17. Marsden AL, Reddy VM, Shadden SC, Chan FP, Taylor CA, Feinstein JA. A new multiparameter approach to computational simulation for Fontan assessment and redesign. Congenit Heart Dis. 2010;5:104-17.

18. Yang W, Chan FP, Reddy VM, Marsden AL, Feinstein JA. Flow simulations and validation for the first cohort of patients undergoing the Y-graft Fontan procedure. J Thorac Cardiovasc Surg. 2015;149:257-65. 


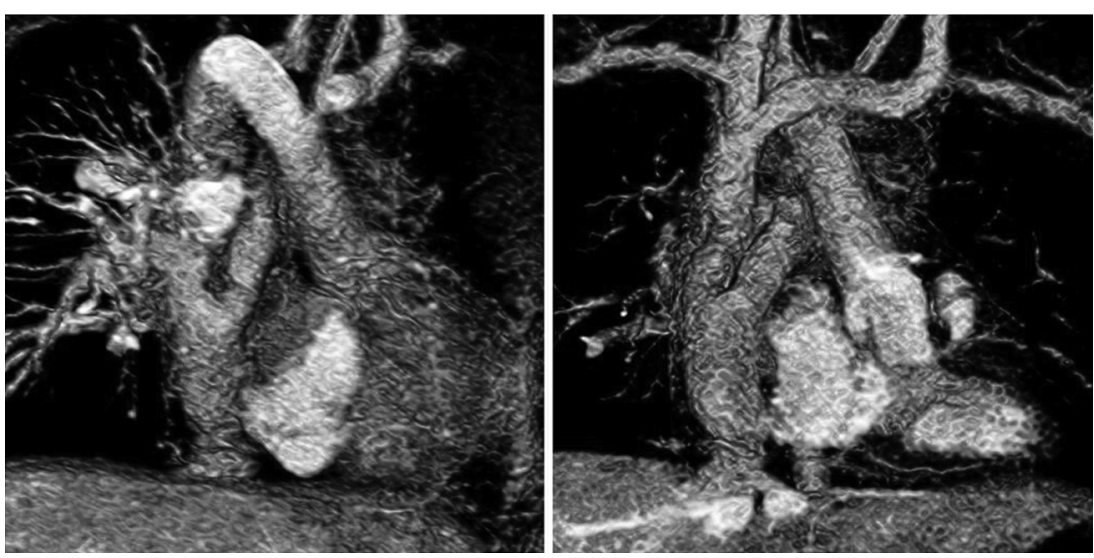

FIGURE E1. Two selected examples of 3-dimensional reconstructions of the Y-graft anatomy.
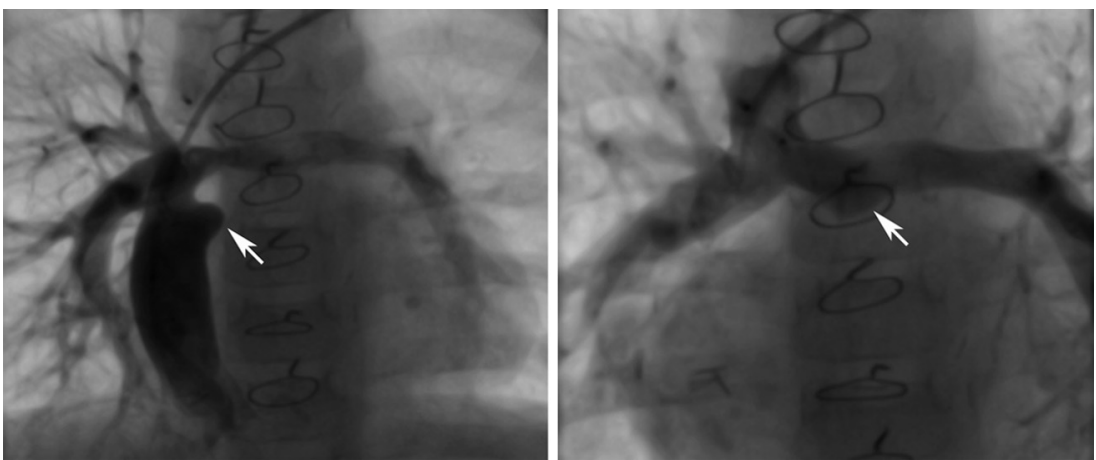

FIGURE E2. Angiography confirms occlusion of the left limb in patient 5. Left, Arrows represent the inferior stump of the limb. Right, Superior stumps of the limb. 